\title{
PROTOTYPE PERANCANGAN SISTEM OTOMATIS PEMBACA SUHU RUANGAN MENGGUNAKAN OUTPUT KIPAS DAN SENSOR LM35 BERBASIS MIKROKONTROLER ATMEGA 16
}

\author{
Ageng Setiani Rafika ${ }^{1}$ \\ Sudaryono $^{2}$ \\ Wisnu Dwi Andoyo ${ }^{3}$ \\ e-mail: agengsetianirafika@raharja.info,sudaryono@raharja.info,wisnudwiandoyo@raharja.info
}

Diterima : 3 November 2014/ Disetujui : 21 November 2014

\begin{abstract}
The fan is a tool that we usually find in everyday life. This is because the fan is a tool commonly used to lower the temperature or refrigerate something. However, the current use of the fan can be developed into a cooling device that can be controlled using an electronic device such as a microcontroller. Therefore we need a system for room temperature control in order to create a good temperature in conducting cooling system. Not just make the climate control, but also made the monitoring system. The data obtained from the LM35 temperature sensor is processed and then displayed in real time in the form of graphs and tables that can be seen by the computer using an LCD that can show the actual temperature in a room that has been installed LM35 sensor. Atmegal6 microcontroller used is an 8-bit microcontroller which has a high capability and low power, in addition to all of the instructions executed in one clock cycle. AVR has 32 general-purpose registers, timer / counters flexible with compare modes, internal interrupt and power saving mode, the internal ADC and PWM. AVR also has in programmable system-on-chip flash program memory allows the system to be re-programmed using the serial SPI relationship.
\end{abstract}

Key Words: Fan,Temperature,LCD , LM35, grafik real time, Atmega16

\begin{abstract}
ABSTRAK
Kipas merupakan alat yang biasa kita temukan dalam kehidupan sehari-hari. Hal ini dikarenakan kipas adalah alat yang biasa digunakan untuk menurunkan suhu atau mendinginkan sesuatu. Namun saat ini penggunaan kipas bisa dikembangkan menjadi alat pendingin yang bisa di kendalikan menggunakan perangkat elektronik seperti mikrokontroler. Oleh karena itu diperlukan sebuah sistem pengendalian suhu untuk ruangan agar dapat tercipta suhu yang baik dalam melakukan sistem pendinginan. Bukan hanya sekedar membuat pengendali suhu, namun juga dibuat sistem monitoringnya. Data yang didapat dari sensor suhu LM35 diolah kemudian ditampilkan berupa grafik real time dan tabel yang dapat dilihat dengan komputer menggunakan LCD yang dapat menunjukkan suhu yang sebenarnya pada suatu ruangan yang telah di pasang sensor LM35. Mikrokontroler atmega16 yang digunakan merupakan mikrokontroler 8 bit yang memiliki kemampuan tinggi dan daya yang rendah, selain semua instruksi dieksekusi dalam satu siklus Clock. AVR mempunyai 32 register general-purpose, timer/counter fleksibel dengan mode compare, interrupt internal dan mode power saving, ADC dan PWM internal. AVR juga mempunyai insystem programable flash on-chip yang mengijinkan memori program untuk diprogram ulang dalam sistem menggunakan hubungan serial SPI.
\end{abstract}

Kata Kunci : Kipas, suhu,LCD , LM35, grafik real time, Atmega16 


\section{PENDAHULUAN}

Seiring dengan berkembangnya ilmu dan teknologi belakangan ini, sistem kendali memiliki peranan yang sangat vital, karena dapat menunjang segala aktifitas yang dilakukan oleh manusia. Contoh nyata dalam kehidupan sehari-hari yang dapat kita lihat adalah penggunaan televisi dengan remote control, penggunaan alat kendali tersebut dirasa efisien bagi manusia. Selain itu kita bisa lihat aplikasi kontrol yang lebih besar yaitu pada perusahaan dalam bidang manufaktur serta pengendali proses seperti tekanan, suhu/temperatur, dll.

Sistem kendali digunakan untuk memelihara/menjaga kestabilan nilai keluaran sistem (measured value) agar berada pada harga yang telah ditentukan (setting value). Sistem ini memiliki sifat dasar bahwa sebuah sinyal penggerak konstan akan menghasilkan keluaran yang berharga konstan. Sistem kendali akan bekerja untuk menjaga agar kesalahan yang terjadi berada pada harga seminimum mungkin. Dalam sistem kendali diperlukan suatu besaran-besaran yang memerlukan kondisi/persyaratan khusus. Persyaratan khusus yang dimaksud yaitu sistem kendali harus stabil, yaitu mempunyai harga yang konstan untuk selang waktu tertentu, sensitif terhadap gangguan, cepat dalam merespon perubahan variabel-variabel sistem dan akurat dalam menampilkan nilai keluaran sistem. Sering terjadi permasalahan dalam sistem kendali terjadi overshoot/undershoot yang besar sehingga kemungkinan dapat terjadi osilasi yang tinggi. Dengan osilasi yang semakin tinggi, maka recovery time/transient time yang dibutuhkan oleh sistem untuk mencapai kondisi steady state juga akan semakin lama. Dengan kondisi demikian, dapat dikatakan sistem tidak memenuhi syarat-syarat dalam suatu pengendalian.

\section{LANDASAN TEORI}

Menurut Anton Pardede (2008:13), Sistem berasal dari bahasa Latin (systema) dan bahasa Yunani (sustema) adalah suatu kesatuan yang terdiri komponen atau elemen yang dihubungkan bersama untuk memudahkan aliran informasi, materi atau energi. Istilah ini sering dipergunakan untuk menggambarkan suatu set entitas yang berinteraksi, di mana suatu model matematika seringkali bisa dibuat.

Menurut Anjar Wisnu Wardani (2008:23), 'disalah satu blog-nya menjelaskan Desain Sistem dapat dibagi menjadi dua bagian, yaitu:

\section{Desain Sistem Secara Umum ( General System Design ) \\ 2. Desain Sistem Secara Rinci ( Detailed System design)}

\section{Tujuan Desain Sistem}

Desain sistem mempunyai tujuan utama yaitu:

1. Untuk memenuhi kebutuhan pemakai sistem. Tujuan ini adalah tujuan dari desain sistem secara umum (General System Design ). (Anjar Wisnu Wardani , 2008:23)

2. Untuk memberikan gambaran yang jelas dan rancang bangun yang lengkap kepada programmer komputer dan ahli-ahli teknik lainya yang terlibat. (ITKOM , 2009:23)

3. Tujuan ini adalah tujuan dari desain sistem secara rinci. (Anjar Wisnu Wardani, 2008:23)

Pekerjaan desain sistem dilakukan oleh analis sistem dan personil-personil teknik lainnya: seperti spesialis pengendalian, personil penjamin kualitas, spesialis komunikasi data.

Tekanan desain adalah tekanan-tekanan yang harus dipertimbangkan dalam mendesain 
suatu sistem informasi supaya mengenai sasarannya.

Adapun tekanan-tekanan tersebut adalah:

\section{a. Integrasi}

Sistem informasi harus di desain terpadu diantara unit-unit didalam organisasi. Untuk hubungan antara unit-unit organisasi dapat dihubungkan dengan berkomuninasi yang baik, baik secara sistem maupun secara data. (Bernaridho I. Hutabarat, 2008:104)

\section{b. Jalur Pemakai}

Sistem yang didesain harus memperhatikan personil pemakai sistem, dimana pemakai mengharapkan dapat dengan baik dilayani segala kebutuhannya oleh sistem makanya diharapkan sistem harus fleksibel, konsisten dan harus mudah dipahami oleh user.

Menurut (Bernaridho I. Hutabarat, 2008:104), 'Berikut ini beberapa yang harus dipertimbangkan dalam memenuhi user interface.

Perancangan sistem otomatis pembaca suhu ruangan menggunakan output kipas dan sensor LM35 berbasis mikrokontroler Atmega 16 adalah alat yang dapat mendeteksi suhu yang berbasis mikrokontroler yang menggunakan Atmega 16 dan sensor suhu LM35. Pembaca suhu ruangan ini bekerja saat udara di sekitar terjadi perubahan. Kipas yang berputar akan menyesuaikan suhu yang terbaca pada LCD. Jika suhu meningkat maka putaran kipas akan semakin kencang, apabila suhu terjadi penurunan maka putaran akan melambat sesuai penurunan suhu yang terjadi. Proses berputar nya kipas dengan kecepatan cepat atau lambat sangat tergantung pada sebuah sensor suhu. Sensor suhu yang digunakan adalah LM35. Karena dari sensor LM35 suhu dapat diketahui pada tampilan pada LCD yang kemudian di lanjutkan proses output dari suhu yang terjadi yaitu berputarnya kipas yang berfungsi sebagai pembaca suhu ruangan.

Penelitian sebelumnya dilakukan oleh Pandu Mayor Hermawan dengan judul "Sistem Pengkondisi Suhu Dan Kelembaban Udara Pada Ruangan Menggunakan Mikrokontroler AT89C51". Dalam penelitian ini

Digunakan keypad sebagai input untuk menentukan nilai suhu yang diinginkan. Namun dalam penelitian ini masih kurang optimal di karenakan kontrol yang digunakan masih menggunakan pompa motor manual.

Penelitian perancangan sistem otomatis pembaca suhu ruangan menggunakan output kipas dan sensor LM35 berbasis mikrokontroler Atmega 16 berkaitan dengan penelitian yang di lakukan oleh Pandu Mayor Hermawan, hanya saja pada ini dikembangkan dengan mengubah control yang dilakukan menggunkan kipas yang akan bergerak pada suhu tertentu sesuai program, kemudian kipas akan bekerja mengikuti besarnya kenaikan suhu yang akan mempengaruh putaran kipas.

\section{PERMASALAHAN}

Sepintas mungkin metode kipas merupakan alat yang biasa gunakan saharihari dalam banyak hal di segala tempat yang berfungsi untuk meberikan kesejukkan udara atau sistem pendingin. Tetapi sebenarnya, dalam penggunaannya kipas bisa kita buat dengan lebih baik dan fungsional dalam membantu kehidupan manusia bisa lebih mempermudah dalam kegunaan dan efesiensi waktu. Sebagai salah satu contoh permasalahan, kita ambil permasalahan saat orang akan mengganti suatu putaran kipas yang di inginkannya sesorang harus memutar atau memencet tombol pada kipas, diantaranya:

1. Untuk saat ini masalah kritis penggunaan kipas yang ada masih 
manual, sehingga memerlukan tenaga seseorang untuk mengontrol kipas tersebut. Contohnya ketika seseorang sedang kelelahan, hal ini memberatkan orang tersebut karena harus mengontrol secara manual seperti harus berdiri atau bangun dari tempat istirahatnya. Oleh karena itu sistem pembaca suhu ruangan menggunakan output kipas dan sensor $\operatorname{lm} 35$ berbasis mikrokontroler atmega 16 sangat membantu seseorang dalam kehidupan sehari-hari, karena tidak ada lagi yang dikerjakan secara manual untuk mengontrol kipas. Sistem ini akan berjalan sesuai suhu ruangan, dimana seseorang tidak akan merasa kedinginan atau kepanasan, tidak ada lagi tenaga yang digunakan untuk mengontrol kipas, karena kipas sudah otomatis. Hal ini sangat mempermudah manusia dalam kehidupan sehari-hari .

2. Dalam proses berputarnya sistem kipas, kipas yang berputar masih berdasarkan kebutuhan seseorang dalam penggunaannya yang ke akuratan suhu yang di inginkan kadang tidak sesuai kebutuhan yang di harapkan pada kipas yang di gunakan.

3. Pada saat kipas berputar kipas hanya berputar begitu saja tanpa menyesuaikan suhu udara sekitar, yang bisa diharapkan untuk mencapai keadaan suhu yang di inginkan yang berdasarkan dingin atau panasnya udara yang terjadi.

4. Selain hal-hal tersebut, di butuhkan tampilan yang menarik pada suatu sistem kipas dan lebih fungsional bukan hanya alat penyejuk udara saja tetapi bisa sebagai pendeteksi suhu udara digital.

Alat pendeteksi suhu menggunakan output kipas seharusnya dapat diterapkan dalam kebutuhan penyejuk udara yang biasa digunakan dalam kehidupan sehari-hari agar dapat menyesuaikan suhu yang diinginkan dapat tercapai tanpa perlu mengganti pengaturan kecepatan kipas dengan tombol yang membutuhkan waktu, dan kurang efesien dalam penggunaannya.

\section{LITERATURE REVIEW}

Banyak penelitian yang sebelumnya dilakukan mengenai alat pendeteksi suhu ruangan. Dalam upaya pengembangan alat pendeteksi suhu ruangan ini perlu dilakukan studi pustaka sebagai salah satu dari penerapan metode penelitian yang akan dilakukan. Diantaranya adalah mengidentifikasikan kesenjangan, menghindari pembuatan ulang, mengidentifikasikan metode yang pernah dilakukan, meneruskan penelitian sebelumnya, serta mengetahui orang lain yang spesialisasi dan area penelitiannya sama dibidang ini. Beberapa Literature review tersebut adalah sebagai berikut :

1. Penelitian ini dilakukan oleh Enis fitriani dari Universitas Narotama Surabaya, pada tahun 2012 yang berjudul " Rancang Bangun Data Akuisisi Temperatur 10 Kanal Berbasis Mikrokontroller Atmega 16". Penelitian ini membahas alat ukur suhu dengan sepuluh sensor, dimana alat ukur suhu ini dapat mengukur sekaligus menampilkan satu persatu data dari sepuluh lokasi yang berbeda[2].

2. Penelitian ini di lakukan oleh Khotib Dahrul Ulum dari Universitas Islam Negeri Sunan Kalijaga Jogjakarta, pada tahun 2013 yang berjudul “" Prototipe Sistem Peringatan Dan Pemadam Kebakaran Ruangan Berbasis Mikrokontroller Atmega 16". Penelitian ini membahas sistem peringatan dalam bentuk SMS. Ketiak 
sensor membaca kepekatan gas dan suhu ruangan masuk dalam level bahaya.

3. Penelitian ini dilakukan oleh Siswoyo dari Universitas Gajahmada Jogjakarta, pada tahun 2014 yang berjudul " Monitoring Suhu Body Transfomator Berbasis SMS". Penelitian ini membahas tentang monitoring suhu body Trasnformator berbasis SMS dan menggunakan Mikrokontroller Atmega 16. Alat ini dibuat untuk mengatasi adanya panas yang melebihi kapasitas suhu Transformator. Ketika sensor mendeteksi suhu yang melebihi kapasitas suhu Transformator maka akan mengaktifkan modem sebagai transmitter berupa sms.

4. Penelitian ini dilakukan oleh Adi Kurniawan dari Universitas Pembangunan Nasiaonal "Veteran" Jawa Timur, pada tahun 2012 yang berjudul Sistem Kendali Suhu dan Kelembaban Untuk Optimasi Proses Pembuatan Tempe Bebasis Mikrokontroller. Penelitian ini membahas tentang pengontrolan sistem yang dilakukan oleh Mikrokontroller Atmega 16 mempunyai input berbentuk sensor sht 11, sensor ini akan mendeteksi suhu dan kelembaban yang berada dalam incubator dan menampilkan pada LCD. Dari hasil pengujian sistem yang telah dilakukan dapat di ketahui bahwa suhu dan kelembaban yang berada dalam incubator dapat berubah mengikuti suhu dan kelembaban yang ada diluar incubator. Pengaturan batas suhu dan kelembaban diatur dalam program juga dapat dirubah menggunkan tombol yang ada pada mikrokontroller.
5. Penelitian ini dilakukan oleh Dendi Satyabima dari Universitas Brawijaya Malang, pada tahun 2014 yang berjudul "Rancang Bangun Rangkaian Pengendali Suhu Air Pada Fotobioreaktor Vertikal". Penelitian ini membahas rangkaian pengendali suhu air menggunakan sensor LM35 dan Mikrokontroller Atmega 16 sebagai pusat kontrolnya dengan maksud untuk mengendalikan suhu air yang dibutuhkan. Prinsip kerja dari alat ini adalah mengendalikan suhu air sehingga tidak melebihi suhu optimal. Sistem kontrol juga juga bekerja dengan baik karena dapat mengontrol keadaan pompa air sesuai dengan suhu yang dibutuhkan.

\section{PEMECAHAN MASALAH}

Ada sebuah konsep yang dipandang dapat mengatasi permasalahan-permasalahan mengenai penyesuaian suhu menggunakan kipas. Konsep tersebut diberi nama alat pendeteksi suhu ruangan menggunakan output kipas. Cara kerja kipas tersebut sama dengan halnya proses berputarnya kipas yang berdasarkan percepatan atau perlambatan putaran kipas, yang di lengkapi dengan alat pendeteksi suhu ruangan menggunakan sensor yang dapat mengetahui suhu udara sekitar. Sebagai contoh, misalnya pada layar suhu dibawah $25^{\circ} \mathrm{C}$ kipas tidak berputar, saat suhu diatas $25^{\circ} \mathrm{C}$ kipas berputar namun dengan putaran yang lambat, sampai kenaikan suhu yang terjadi kipas akan berputar lebih cepat.

Alat pendeteksi suhu ruangan menggunakan output kipas itu sendiri adalah alat yang berfungsi sebagai bagian dalam penggunaan alat penyejuk udara menggunakan kipas. Sehingga memudahkan penggunanya dalam menggunakan alat pendeteksi suhu ruangan menggunakan output kipas yang di perlukan dalam 
kebutuhan sehari-hari dalam berbagai hal yang penggunaannya akan berjalan lebih mudah.

Untuk mengetahui semua permasalahan seperti yang telah di jelaskan, dan demi menciptakan suatu alat yang dapat berguna bagi kehidupan sehari hari yang bisa mempermudah penggunaan kipas agar lebih efesien dan sesuai kebutuhan yang diinginkan. Oleh karena itu, alat pendeteksi suhu ruangan menggunakan output kipas bisa di terapkan untuk peningkatan efektifitas alat yang di buat. Selain mempermudah dalam penggunaannya, hal ini juga dapat memecahkan permasalahan yang terdapat pada sistem kipas yang masih menggunakan tombol dalam pengoperasiannya yang masih sering kita gunakan sampai saat ini.

Kelebihan-kelebihan dari alat pendeteksi suhu ruangan menggunakan output kipas adalah:

1. Alat pendeteksi suhu menggunakan output kipas mendapat inputan dari sensor yang akan memunculkan realita suhu pada layar LCD, maka pengguna bisa mengetahui suhu diruangan sekitar yang dapat membaca kenaikan suhu yang terjadi. (tambahan dari bu ageng)

2. Pengguna juga tidak perlu merubah pengaturan kipas yang memerlukan waktu dan energi dalam proses penggunaannya.

3. Pengguna lebih mudah dalam penggunaan alat pendeteksi suhu menggunakan kipas karena alat tersebut dapat menyesuaikan suatu kipas cepat atau lambatnya kecepatan kipas dalam putaran berdasarkan inputan dari sensor yang dibaca pada layar LCD sehingga proses penggunaannya kipas dapat berputar secara otomatis yang bisa meyesuaikan dengan suhu yang terjadi pada suatu ruangan.
4. Dibuatnya sistem kipas yaitu dengan alat pendeteksi suhu ruangan menggunakan output kipas agar bisa bermanfaat dalam kehidupan seharihari yang selama ini masih banyak digunakan penyejuk udara menggunakan kipas, tapi proses penggunaannya masih perlu mengoperasikan dengan cara manual yang mungkin kurang efesien dari segi waktu dan membutuhkan energy lebih penggunanya dalam memenuhi kebutuhan alat penyejuk udara.

5. Alat pendeteksi suhu ruangan menggunakan ouput kipas juga mungkin akan menjadi alat yang bisa berguna yang dapat mendukung sebuah alat yang sederhana namun memiliki keunggulan dalam penggunaannya tanpa harus mengubah pengaturan yang masih banyak digunakan pada teknologi sistem kipas yang masih digunakan sampai saat ini.

\section{IMPLEMENTASI}

Implementasi dari penguraian di atas adalah dengan membuat sistem alat pendeteksi suhu ruangan menggunakan output kipas, penanganan kekurangan dalam penggunaan kipas sederhana dapat diminimalisir menggunakan alat pendeteksi suhu menggunakan output kipas.Alat pendeteksi suhu ruangan menggunakan output kipas merupakan alat yang harus dikembangkan oleh produsen produsen kipas yang masih menggunakan kipas yang pengoperasiannya masih dilakukan secara manual.

Hasil akhir yang ingin dicapai dari adalah membuat alat lebih bermanfaat dengan fungsi yang bukan hanya sekedar kipas. Karena itulah, untuk dapat meggunakan alat pendeteksi suhu menggunakan output kipas dengan cara yang 
efektif, diterapkanlah alat seperti di bawah ini.

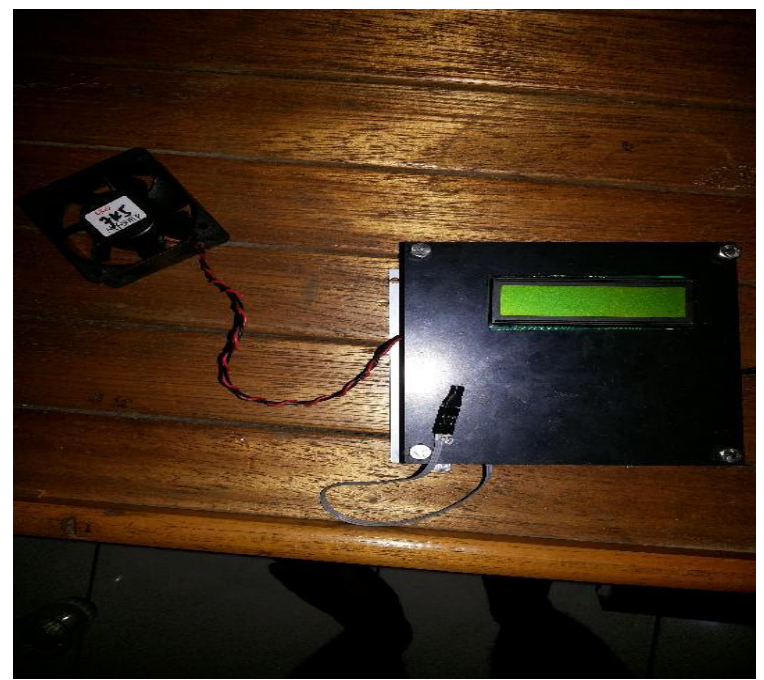

Gambar 1. Alat Pendeteksi suhu menggunakan ouput kipas

Pada Gambar 1 di atas merupakan alat sistem pendeteksi suhu menggunakan output kipas. Dari halaman tersebut dapat diketahui bahwa sensor menerima data dan mengirimkan data tersebut yang muncul pada layar LCD yang kemudian data tersebut di jadikan output dari pembacaan suhu ruangan.

Jika ternyata suhu yang di baca belum tercapai untuk memutarkan kipas maka kipas tidak akan berputar. Dapat dilihat pada gambar 2

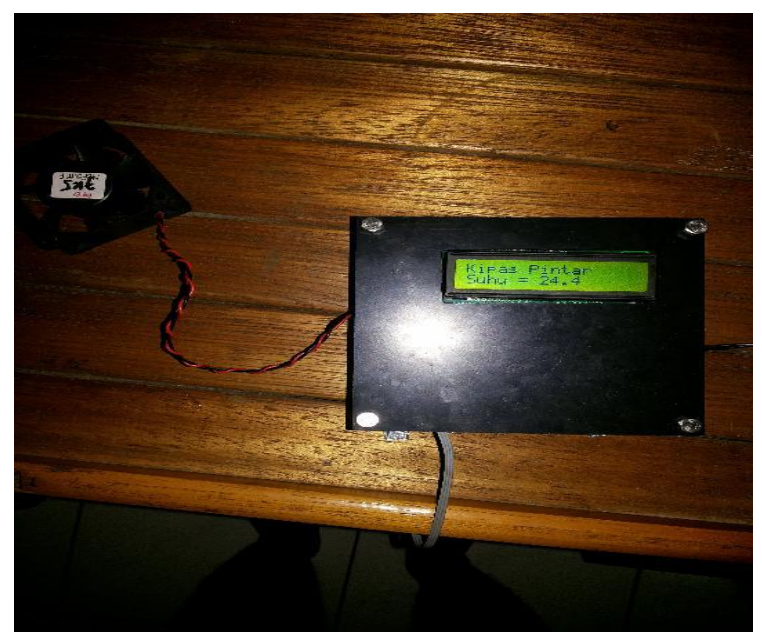

Gambar 2. Kipas belum berputar pada suhu di bawah $25^{\circ} \mathrm{C}$
Tetapi lain halnya jika suhu yang telah di capai sudah melebihi $25^{\circ} \mathrm{C}$, maka dengan perlahan kipas membaca perintah yang di terima dan kipas berputar dengan perlahan. Berikut tampilannya.

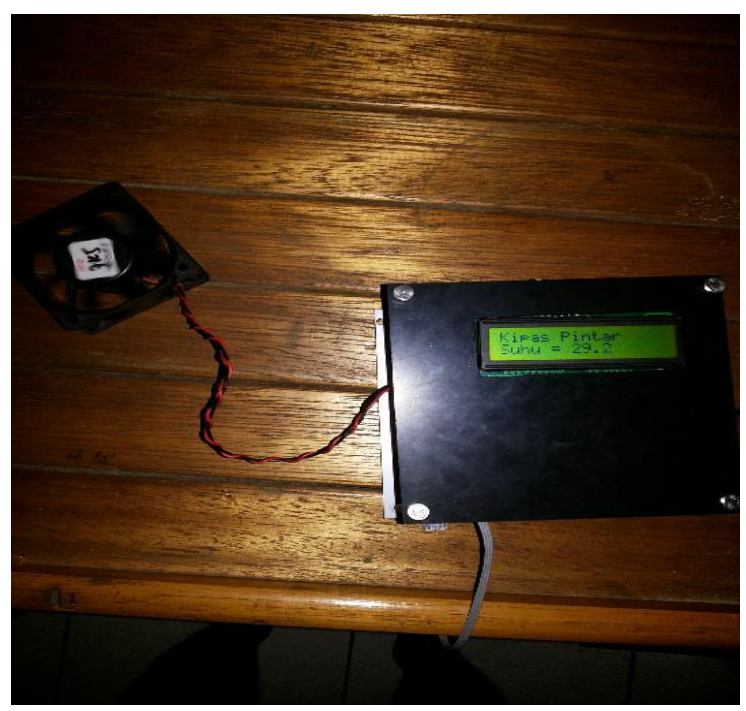

Gambar 3. Suhu sudah diatas $25^{\circ} \mathrm{C}$

Pada gambar 3 tersebut dihasilkan proses-proses terjadinya putaran pada sebuah kipas yang akan berputar mengikuti kenaikan suhu yang terjadi. Hasil dari peningkatan suhu yang terjadi maka perubahan tersebut dapat dilihat pada gambar 4 .

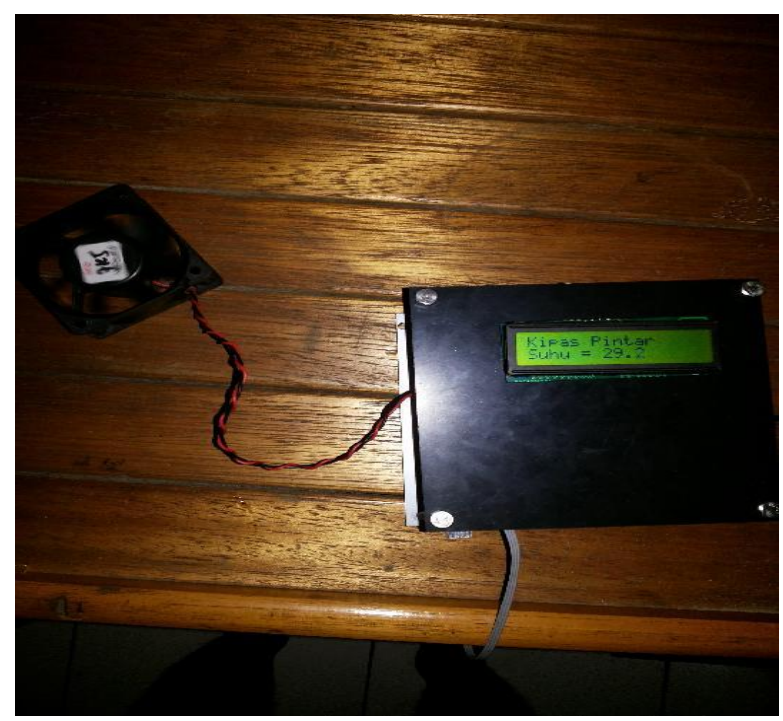

Gambar 4. Suhu diatas $30^{\circ} \mathrm{C}$ 
Blok Diagram

\section{Pembaca Suhu Menggunakan Kipas}
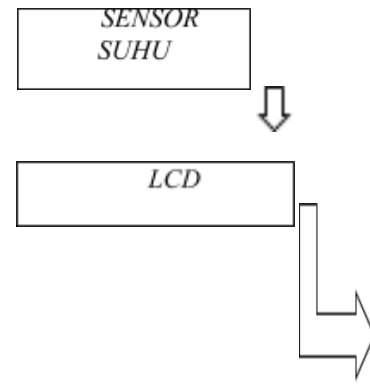

Gambar 5. Blok Diagram Pembaca Suhu Ruangan Menggunakan Kipas

\section{Flow Chart Sistem Pembaca Suhu Menggunakan Kipas}

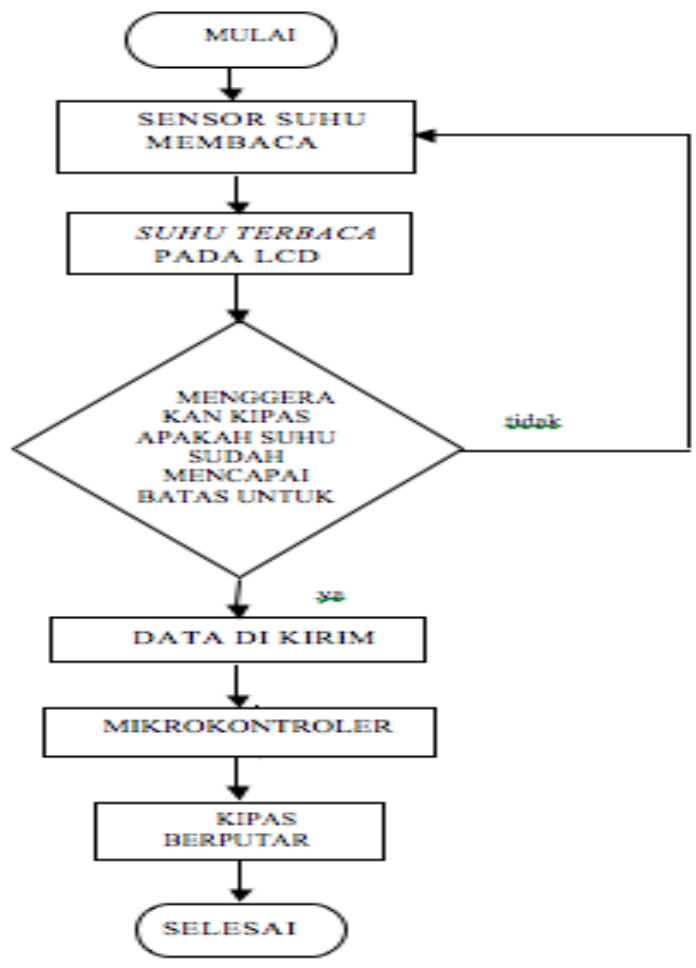

Gambar 6. Flow Chart Sistem

\section{Listing Program}

Whow

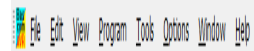

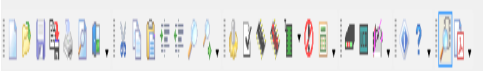

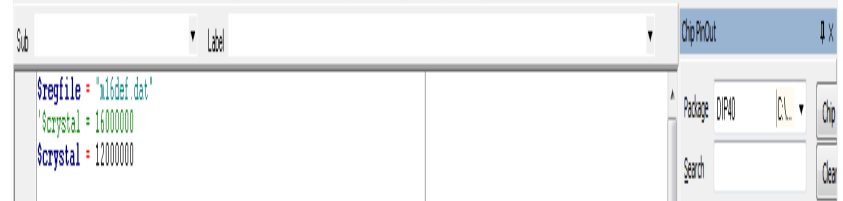

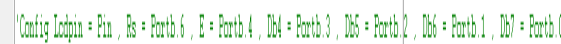

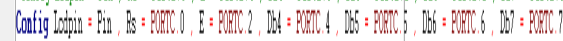
Config then: : !

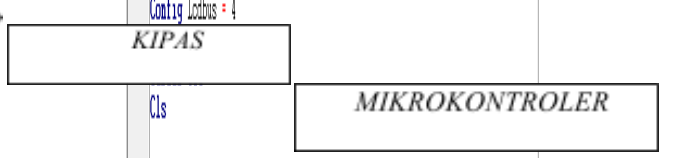

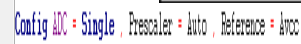

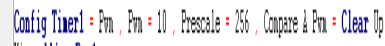
lirw lisis hila

\section{Cons thit: 0}

Const ilan : :III)

Cont tatan: =111

Cast lexpy: :10:3

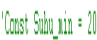

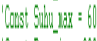

Const minis: :30

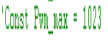

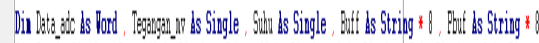

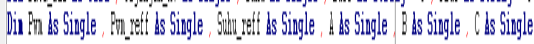

Start ill

bearil:

do

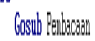

Bit: Pring gin, 4.6

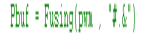

Ipperline

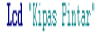

Loserline

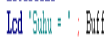

Viaths ill

Lapp

babsen

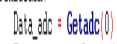

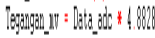

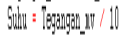

"ustibs

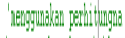

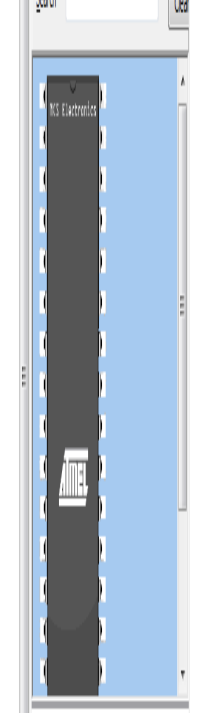

Pembaca Suhu Ruangan Menggunakan

Kipas 


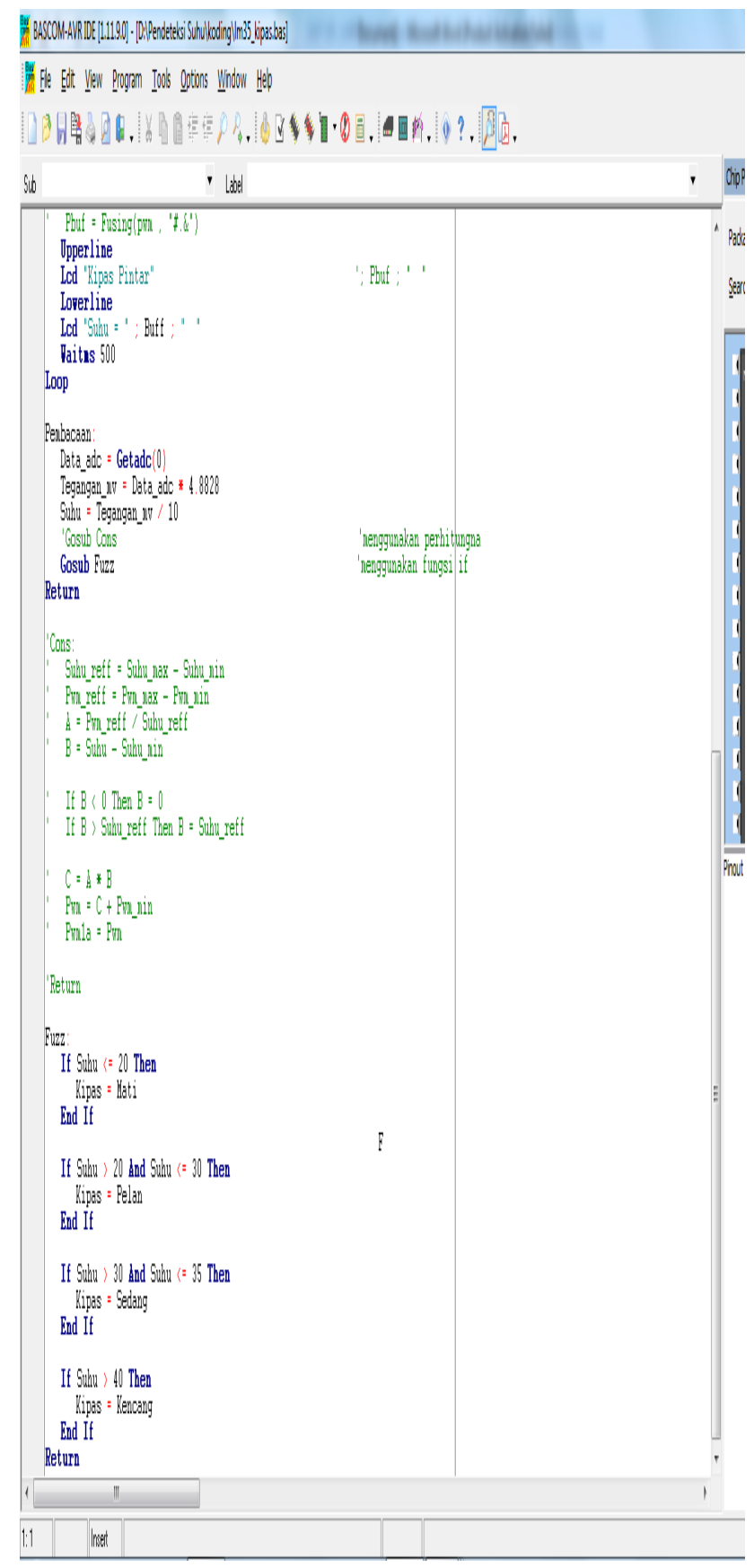

Gambar 7. Listing Program

Dari kondisi yang terjadi sesuai dengan urutan gambar gambar diatas, maka dapat disimpulkan bahwa kipas benar berputar mengikuti perubahan yang terjadi sesuai kenaikan atau penurunan suhu yang terjadi dengan begitu alat tersebut memang bisa membantu mengefesienkan dan menghemat energy penggunanya dalam menggunakan alat pendeteksi suhu ruangan menggunakan output kipas.

\section{KESIMPULAN}

Alat pendeteksi suhu ruangan menggunakan output kipas merupakan salah satu bagian penting pada proses penyejuk udara yang biasa dibutuhkan banyak orang. Cara kerjanya yang mengefektifkan penggunanya dalam pengoperasian alat tersebut dapat membantu untuk semua konsumen. Alat pendeteksi suhu ruangan menggunakan output kipas sangat tepat apabila bisa digunakan saat ini. Hal ini sangat membantu karena selain menghemat waktu dan tenaga alat pendeteksi suhu menggunakan output kipas dapat memenuhi keinginan pengguna tanpa harus mengaturnya secara manual dalam menyesuaikan perputaran kipas dan menyesuaikan suhu untuk menyejukkan ruangan.

\section{DAFTAR PUSTAKA}

1. F. Enis, T. Didik, W. Slamet. "Rancang Bangun Data Akuisisi Temperatur 10 Kanal Berbasis Mikrokontroller Atmega 16", Jurnal Monitor Vol.1 No.1 Juli. Universitas Narotama : Indonesia, 2012.

2. U.B. Khotib, "Prototipe Sistem Peringatan Dan Pemadam Kebakaran Ruangan Berbasis Mikrokontroller Atmega 16" Jurusan Teknik Informatika, Skripsi, Jogjakarta : UIN Sunan Kalijaga, 2013.

3. Siswoyo, "Monitoring Suhu Body Transformator Berbasis SMS" Jurusan Teknik Elektro, Tugas Akhir, Jogjakarta : Universitas Gajah Mada 2014.

4. K. Adi, "Sistem Kendali Suhu Dan Kelembaban Untuk Optimasi Proses 
Pembuatan Tempe" Jurusan Teknik Informatika, Skripsi, Jawa Timur : Universitas Pembangunan Nasional 2012.

5. S. Dendy, S. Bambang, H. Yusuf. "Rancang Bangun Rangkaian Pengendali Suhu Air Pada Fotobioreaktor Vertikal", Jurnal Keteknikan Pertanian Tropis Dan Biosistem Vol.2 No.3 Oktober. Universitas Brawijaya : Indonesia 2014 